\title{
A Delphi Approach to the Selection of Good Agricultural Practices (GAPs) for Resilience Enhancement for Dry Land Farmers in North-Western Nigeria
}

\author{
Nugun Patrick Jellason ${ }^{1,2}$, Richard N. Baines ${ }^{1}$ and John S. Conway ${ }^{1}$ \\ 1. Royal Agricultural University, Stroud Road, Cirencester GL7 6JS, Gloucestershire, England \\ 2. National Biotechnology Development Agency, Lugbe, Umar Musa Yar'Adua Road, Abuja 900107, Nigeria
}

\begin{abstract}
An earlier baseline study (Jellason et al. in preparation) has identified some of the key challenges faced by farmers and from that, appropriate Good Agricultural Practices (GAPs) have been selected for the environment the farmers find themselves in and based on a review of available literature. Farmer action plans for enhancing smallholder resilience, GHGs emission mitigation and food security for these dry lands were developed. Expert opinions on the applicability of the selected GAPs to inform farmer co-learning and to validate the suitability of these practices in a dry land context were sought through the Delphi study. Experts were also invited to offer suggestions for improvement of the training action plan. Two rounds of a modified Delphi survey were carried out with experts from diverse backgrounds and locations across the globe to solicit their opinion. Results show that experts' agreement was reached on most of the action plan items. The results and opinions obtained from the survey were reviewed and adapted into the action plan leading to the development of GAPs for the co-learning exercise.
\end{abstract}

Key words: Delphi technique, good agricultural practices, mitigation, resilience, dry lands, food security.

\section{Introduction}

In conservation science studies, expert knowledge has been found to be useful to overcome problems of data unavailability [1] and the exigency around decision making on conservation issues [2]. An expert according to Martin et al. [2] "is someone who holds this knowledge and who is often deferred to in its interpretation". The Delphi technique, on the other hand, refers to an iterative process of seeking expert opinion through the use of well-crafted questionnaires [3-6] to form a consensus on a certain topic that is still valid [7]. The method is not only a data collection process but provides an opportunity for a group of experts to brainstorm over a complex problem [8]. Despite similarity with focus group discussions in eliciting group responses as opposed to an individual response [9], there are slight differences as expert

Corresponding author: Nugun Patrick Jellason, doctoral candidate, research field: food systems resilience. panels are formed in a structured way [10] to seek clarity on reasons for a divergent opinion [3]. While in Delphi studies there is independence of expert opinions, dominant participants influence each other in focus group discussions in a group dynamic. Also, individuals in each round of Delphi can be drawn from a wider location and do modify their views based on feedbacks received.

No consensus in the literature has been reached on the number of participants in a Delphi panel [3] as the minimum number of panel members is dependent on the study design [4]. Panels can be made up of 15 to 35 participants in some cases [11] while in others it could range from seven [12] to 115 panellists [13]. Delphi methodology's strengths lie in the fact that it does not require participants to be brought together and its democratic nature which helps in bringing together mutual knowledge in the discipline, hence, "facilitating inter-professional communication" [5]. Despite these strengths, the lack of understanding of 
the consensus-making process leads some to question the rigor in this methodology [5].

The overall aim of using the Delphi technique in this study was to seek expert opinion on whether the Good Agricultural Practices selected from scientific review were appropriate for tackling environmental challenges of agriculture identified in the study communities. As available evidences show, Good Agricultural Practices (GAPs) have benefit for soil fertility and water conservation in marginal conditions. Other objectives included:

- To understand from expert perspective if farmers in these areas already use these GAPs and if not whether they need support to adopt and adapt the GAPs;

- To explore from experts' view if farmers in these regions generally need further training on the GAPs and if yes what methods are appropriate for the training;

- To ascertain whether the selected GAPs have the potential for greenhouse gas mitigation in those areas.

\section{Materials and Methods}

A baseline survey was initially carried out to understand the current use of GAPs in the study communities (Zango and Kofa). The Delphi technique was subsequently used to seek expert opinion on the validity of the GAPs chosen and on how they could result in resilience enhancement of dry lands agriculture.

\subsection{Design of the Good Agricultural Practices (GAPs)} Action Plan

A GAPs action plan was designed for sub-Saharan African dry land farmers to be used as a means of engaging with the farmers on how to remedy their dry land environmental challenges as highlighted in the baseline study. A detailed review of the literature as suggested by Hsu and Sandford [3] was done around GAPs for dry lands management as the first round of the Delphi technique. This is because it is suggested that if an existing list of the items of interest is available, the first round can be "by-passed" [4], hence, making the methodology a potentially two-round Delphi process [14]. Most Delphi studies do not exceed two rounds as experts are busy and unwilling to participate in more rounds [15]. Based on available evidence from literature, GAPs for tropical dry lands management were selected and linked to the associated benefits of adoption. The study was carried out in the context of tropical dry lands to allow for high response rate as most experts at the second round signified a lack of specific knowledge of northern Nigerian dry lands. Since it is important to contact experts at least twice with the same questions in order to review their previous responses based on the responses of other experts in the panel [7], two rounds of the Delphi were carried out.

The GAPs action plan questionnaire contained a total of 19 main questions with 6 questions having sub-sections. The questions were on topics related to:

(1) GAPs overview.

(2) Training on GAPs.

(3) Suitability of GAPs for soil fertility management.

(4) The importance of GAPs for degraded land restoration.

(5) The importance of GAPs for rainfall and drought management.

(7) The importance of GAPs for pests and diseases management.

(8) Suitability of GAPs for GHGs mitigation.

(9) Additional GAPs suggested.

(10) Area of specialization of the respondent.

(11) Current sector respondent is employed in and;

(12) Respondent's interest to participate in the study and previous experience on GAPs training.

Based on claims in the literature, selected practices were presented to the experts, along with 4 point Likert scales [16] where experts could agree or disagree with the GAP chosen. A further section allowed them to justify scoring and offer alternatives 


\section{A Delphi Approach to the Selection of Good Agricultural Practices (GAPs) for Resilience Enhancement for Dry Land Farmers in North-Western Nigeria}

appropriate for ranking. Hence, the Delphi survey was carried out to validate the GAPs chosen so that the training and action planning intervention will be evidence based. Being a methodology that seeks expert opinion based on their experiences and expertise and not aimed at generalizing findings, the results of the Delphi were subject to descriptive statistical analysis [9]. For each question calculated along with the absolute number of experts that reached agreement. The summary of the rounds is presented in Table 1.

\subsection{The Approach to Delphi Technique}

\subsubsection{Expert Selection and Sampling}

A panel of experts were invited to take part in a
Delphi study (Table 2) in order to gather evidence on which GAPs were needed by the target farmers, their opinions on farmers' current knowledge of GAPs, whether training is needed for dry land farmers, and the importance of incorporating farmers' input into the design of the training on the GAPs selected. Experts were also prompted to comment on the ideal methods of training, and suitability for tackling the environmental challenges faced by farmers in sub-Saharan African dry lands which include:

(1) Soil fertility problems.

(2) Land degradation.

(3) Low rainfall and drought.

(4) Pests and diseases.

(5) Greenhouse gas emission.

Table 1 Delphi rounds.

\begin{tabular}{|l|l}
\hline Round I & Review of literature on GAPs for dry land management.
\end{tabular}

Round II $\quad$ Experts' ranking of the GAPs and their suitability for GHGs mitigation and approach to training with suggestions given.

\begin{tabular}{|l|l|l}
\hline Round III & Feedback from reviewing the second round with suggestions given until consensus is reached.
\end{tabular}

Table 2 Characteristics of the GAPs experts in the Delphi rounds.

\begin{tabular}{|c|c|c|}
\hline & $\begin{array}{l}\text { Round II }(\mathrm{n}=11) \\
\text { Number of experts } \\
(\%)\end{array}$ & $\begin{array}{l}\text { Round III }(\mathrm{n}=12) \\
\text { Number of experts } \\
(\%)\end{array}$ \\
\hline \multicolumn{3}{|l|}{ Area of expertise ${ }^{1}$} \\
\hline Agronomy & 3 & 3 \\
\hline Soil Science & 3 & 4 \\
\hline Plant Science & - & 1 \\
\hline General Agriculture & 4 & 5 \\
\hline Biology & 1 & 2 \\
\hline Environmental Science & 5 & 6 \\
\hline Others $^{\mathrm{a}, \mathrm{b}, \mathrm{c}, \mathrm{d}, \mathrm{e}, \mathrm{f}, \mathrm{c}}$ & 1 & 4 \\
\hline \multicolumn{3}{|l|}{ Employment } \\
\hline University/College & $4(36)$ & $5(42)$ \\
\hline Research Institution & - & $1(8)$ \\
\hline Government Department & $1(9)$ & $1(8)$ \\
\hline Private company/business & $3(27)$ & $1(8)$ \\
\hline Multinational organisation & $1(9)$ & - \\
\hline Others $^{1,1,1,2,1}$ & $2(18)$ & $3(25)$ \\
\hline \multicolumn{3}{|l|}{ Interests in participating } \\
\hline Yes & $6(55)$ & $12(100)$ \\
\hline No & $1(9)$ & - \\
\hline Maybe & $4(36)$ & - \\
\hline
\end{tabular}

\footnotetext{
1 There were options for multiple choices of areas of expertise, so percentage may not necessarily sum up to 100.
} 
Random selection was not used in selecting the panellists and hence sample representativeness cannot be assured [17]. In most Delphi studies, non-probability sampling is accepted to solicit expert opinions $[18,19]$. Selection of experts was based on the following criteria:

- Researchers in conservation agriculture disciplines and dry lands whose research papers have previously been used by the corresponding author.

- Practitioners in the field of conservation agriculture in Africa.

- Professionals co-nominated by participants in the study [20].

In total, 63 experts were invited through emails to participate in the study where consensus was reached after round 3 which formed the methodology $[14,15]$.

The literature review to develop the questionnaire served as the first round followed by the first questionnaire sent to the 38-panel members to seek their opinions (Table 3 ).

\subsubsection{A Survey of GAPs Experts}

Most of the experts are from a University/College background, research and development professions across Africa and Europe with diverse fields of expertise as they were advised to select more than one option where applicable (Table 2). Experts in the rounds 2 and 3 are mostly from agronomy, soil science, general agriculture and environmental science disciplines. Hence, their opinions on the selected GAPs are highly valued as they have long years of experience and knowledge of these GAPs and their applicability.

\subsection{Round 1}

Findings from the review of the literature on the items to be included show varied GAPs for low rainfall management, soil fertility management, pest management, degraded land restoration and different methods for extension (Fig. 1). This is because first rounds mostly serve to specify matters to be tackled in subsequent rounds [19].

\subsection{Round 2}

The round 2 of the Delphi consisted of a 4-point Likert scale survey questions from a review of the literature [3]. This was to reduce the number of iterations. A potential for bias could arise due to limited options available [21]. However, spaces were given for respondents to suggest additional GAPs for inclusion in the action plan with other relevant comments [22]. Questions for this round were sent out to all the experts invited so that they could rate the selected GAPs, suggest any need for further training and advocate the best approach to training. Experts were required to select and rank the suitability of the GAPs for water, soil fertility, pest and diseases management and degraded land restoration. Options were rated on a 4-point Likert scale based on $(1=$ "Strongly Disagree" and $4=$ "Strongly Agree"). The options were "forced" for experts to make specific choices as there was no option of "Neither agree nor disagree". Furthermore, positive responses and negative responses were grouped together and plotted in a bar graph. It was requested that responses be returned to the researcher as soon as completed for further review and analysis. Suggestions for improvements solicited (Table 4) with email reminders sent to remind those yet to return filled questionnaires to do so.

\subsection{Round 3}

Responses from the round 2 were put together and suggestions from experts were incorporated to increase the level of consensus in the third round, the response

Table 3 Participants in the GAPs for tropical dry lands Delphi studies.

\begin{tabular}{lll}
\hline Delphi panel & GAPs experts invited & Experts responded \\
\hline Invited (Round II) & 38 & $11(29 \%)$ \\
Round III & $11+14$ (recommended) & $(48 \%)$ \\
\hline
\end{tabular}


rate and the strength of the action plan. Response rate at this stage increased from $29 \%$ in the first round to $48 \%$ in the second round. Practices that received less than $50 \%$ consensus in the second round were dropped such as "intensive control livestock grazing (more livestock)" which was replaced by "sustainable pastoralism" as this better reflected smallholder practices. However, the study did not focus on this practice because the communities do not partake in this so it was dropped. Other practices included in the mitigation section of the questionnaire comprised: "intercropping legumes with other crops" and "use of cover crops" as suggested by experts. Results for rounds 2 and 3 are analyzed and presented in Fig. 2. Therefore, by building experts' suggestions into subsequent rounds it helped in building confidence in the study [7].

All items that reached consensus (70\%) at this stage were used for the action plan training for northern Nigerian dry land farmers. All the panel members that responded to the round 3 indicated interest in having the final report of the Delphi study to be shared with them.

\subsection{Limitations of the Delphi Methodology}

Despite the numerous advantages of employing the Delphi technique to collect data in form of expert opinion which include cost effectiveness and time-saving, it is not devoid of limitations. Some of the limitations include: influencing consensus in some cases [4], the process of expert selection could be misleading, and due to the small sample size, findings cannot be generalizable. Hence, the value of the Delphi technique is in the ideas generated [11], and the outcome is as good as the quality of the panel members since it is opinion based [4].

Socio-economic and cultural aspects of GAPs adoption and more focus on crop with less emphasis on animals were some of the issues raised during the rounds that need to be addressed. Some terminologies such as "sustainable", "appropriate" were said to be vague by some panel members and hence defining them could be crucial to avoid bias [1]. Also, the technique is mostly over simplified as it is being viewed by non-expert researchers as an easy method for data collection thereby missing the rigour it entails. Lack of prompt feedback to participants on the findings from the use of Delphi normally discourages participants from participating in future studies making them feel used with nothing in return [7].

\subsection{Potentials of the Delphi Methodology}

Despite the shortcomings of the Delphi technique, it has value in its effectiveness in organizing opinions without physically bringing respondents together due to resources constraint $[18,23]$. Hence, the application of the methodology was used in this study. Group decision making is more superior to aggregate individual responses in Delphi studies. This is because it provides rich data from multiple iterations and revision of responses informed by feedback, while also maintaining the anonymity of responses [9], hence, bringing the responses close to reaching a consensus after each round. However, not being in same room avoids dominance by some individuals.

\section{Results and Discussion}

This section presents results and discussions on the GAPs selection for training and the level of consensus reached at each round.

\subsection{Characteristics of Expert Participants}

Experts in the Delphi study cut across different disciplines which helped in shaping the responses. Most experts are from environmentally related disciplines followed by general agriculture, agronomy, and soil science. Detailed characteristics of the expert respondents are highlighted in Table 2. The spread of experts across disciplines related to the study is not surprising as the study sample is drawn from the sources of literature used by the corresponding author. 


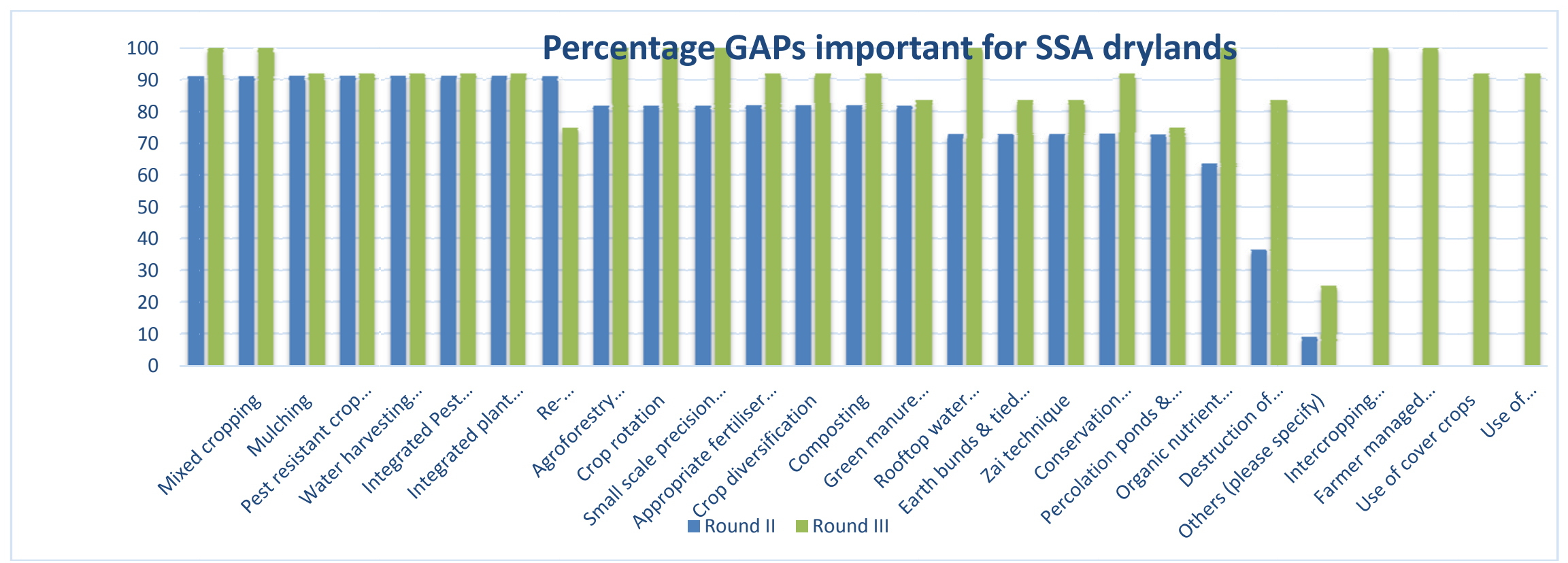

Fig. 1 Important good agricultural practices in sub-Saharan African dry lands assessed using the Delphi technique. 


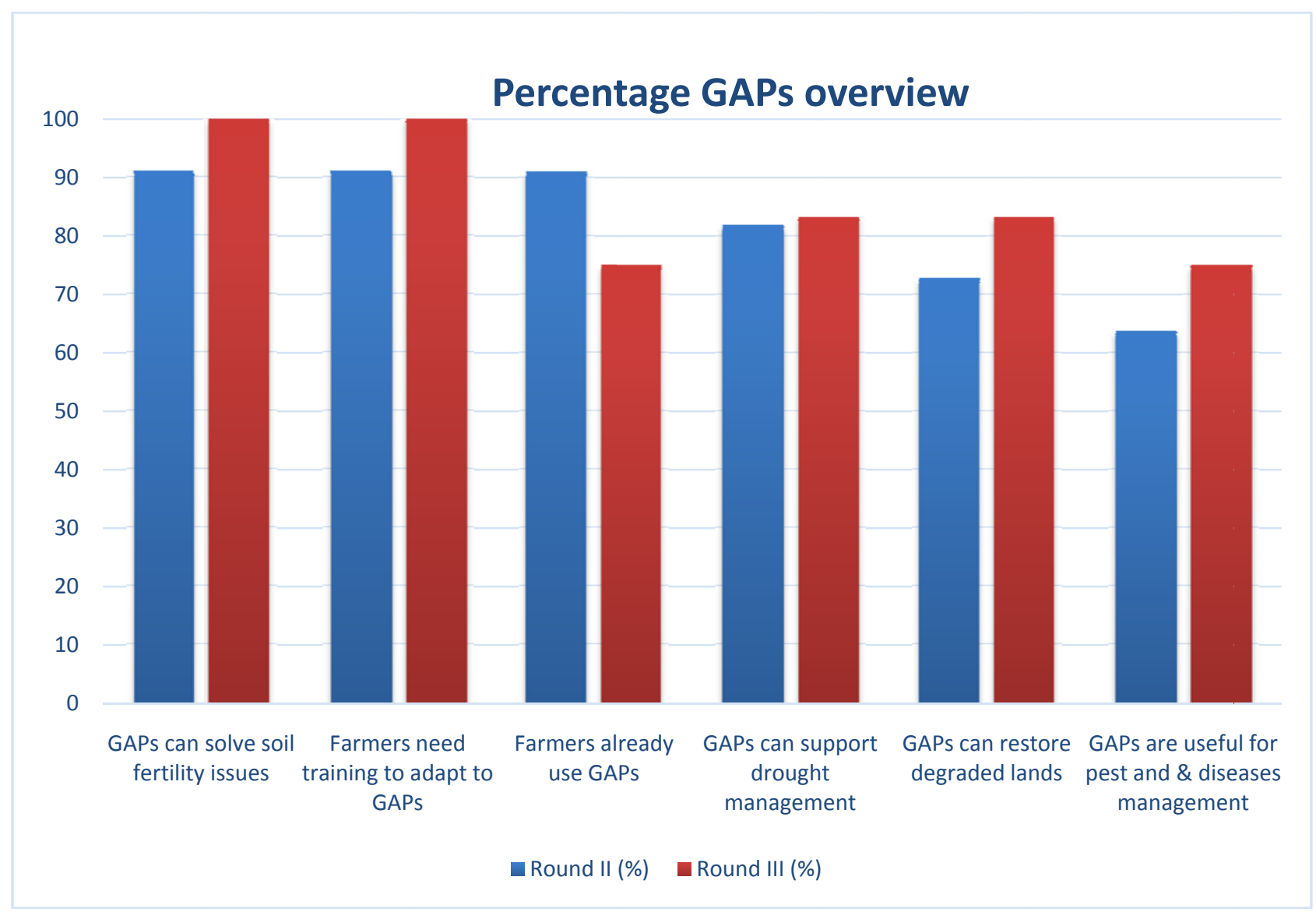

Fig. 2 Good agricultural practices overview round II $(n=11)$, round III $(n=12)$. 


\subsection{GAPs Overview}

Only three items reached consensus in the second round on the importance of the GAPs. However, after suggestions for improving the questionnaire were incorporated for the third round, four items out of six reached consensus which is one item over the second round (Fig. 2). This implies that most experts agreed that GAPs are important for solving soil fertility and drought challenges in tropical dry lands and can also support pest and disease management, and degraded land restoration, hence, making the practices ideal for co-learning exercise.

\subsection{Suggestions for Improvement of Action Plan} Rounds 2 and 3

Table 4 Suggestions for improving the action plan from round 2.

\begin{tabular}{|c|c|c|}
\hline Practice & Expert $(\mathrm{E})$ & Suggestions. \\
\hline \multirow[t]{6}{*}{$\begin{array}{l}\text { Practices under GAPs } \\
\text { overview }\end{array}$} & E2 & There is need to indicate crop specific GAPs for that region. \\
\hline & E3 & $\begin{array}{l}\text { Drought management requires more than GAPs especially in the dry land where water is } \\
\text { highly insufficient. }\end{array}$ \\
\hline & E4 & More GAPs need to be developed. \\
\hline & E5 & GAPs should first be defined and secondly understood and implemented properly. \\
\hline & E9 & $\begin{array}{l}\text { GAPs in dry lands must not focus on crop farming only; mobile pastoralism as a livelihood } \\
\text { strategy and production system is central to reversing land degradation in dry lands. }\end{array}$ \\
\hline & E10 & $\begin{array}{l}\text { Complementary practices are necessary to integrate with GAPs including good extension } \\
\text { methods. }\end{array}$ \\
\hline \multirow[t]{3}{*}{ Training on GAPs } & E3 & $\begin{array}{l}\text { Farmers' knowledge should be considered in GAPs training as they possess more knowledge } \\
\text { than expected. }\end{array}$ \\
\hline & E9 & All training methods are relevant not as stand-alone but integrated where necessary. \\
\hline & E11 & A combination of all these training methods is important, there is no best method. \\
\hline $\begin{array}{l}\text { Farmer to farmer } \\
\text { knowledge exchange }\end{array}$ & E3 & This can be effective as farmers have been learning from each other for generations now. \\
\hline $\begin{array}{l}\text { GAPs for low rainfall } \\
\text { and drought } \\
\text { management }\end{array}$ & E6 & $\begin{array}{l}\text { Zai is important but labour intensive. } \\
\text { And small-scale irrigation depends on the availability of water for irrigation. }\end{array}$ \\
\hline $\begin{array}{l}\text { GAPs for soil fertility } \\
\text { management }\end{array}$ & E1 & $\begin{array}{l}\text { Cover crops with intercropping legumes with other crops are very important here. } \\
\text { Incorporating crop residue into the soil is also very important here. }\end{array}$ \\
\hline \multirow[t]{2}{*}{$\begin{array}{l}\text { GAPs for pests \& } \\
\text { diseases management }\end{array}$} & E6 & Practices should be a combined set of technologies and not separate entities. \\
\hline & E6 & It should read "destruction of diseased crop residue" not "destruction of crop residue". \\
\hline \multirow[t]{2}{*}{$\begin{array}{l}\text { GAPs for degraded land } \\
\text { restoration }\end{array}$} & E9 & $\begin{array}{l}\text { Too focused on crop production and missed livestock production which is a key production } \\
\text { form in these marginal areas. }\end{array}$ \\
\hline & E10 & Natural regeneration is an important practice here. \\
\hline \multirow[t]{2}{*}{ GAPs missed out } & E4 & Appropriate agronomy (weed management, plant spacing). \\
\hline & E6 & Precision planting and early planting. \\
\hline
\end{tabular}

\subsection{The Delphi Survey}

In Table 3 the number of experts invited to participate in the Delphi study and the response rate at each round is indicated. The response rate for second and third rounds (29 and 48 percent respectively) was typical of responses in Delphi studies [15]. In the second round, two experts declined to participate, though one requested to be reminded again but did not respond. There was no information from the other 24 experts invited. From the 11 responses in the second round, 14 additional names were suggested by the participating experts to be invited making the number of invited experts for the third round to be 25 . However, despite sending email reminders on two occasions to increase the response rate, only 12 experts responded to the third round that led to the 


\section{A Delphi Approach to the Selection of Good Agricultural Practices (GAPs) for Resilience Enhancement for Dry Land Farmers in North-Western Nigeria}

development of the final results used for the farmer action plan. As reported in previous studies [18], responses are mostly at the discretion of respondents. Time constraint could probably be the reason for some respondents not responding as two respondents in the round II requested to be reminded for the round III to confirm availability to participate. Using Green's (1982) suggestion cited in Ref. [3], the consensus in this study was taken to be 70 percent of respondents rating 3 or higher in a 4-point Likert scale.

3.4.1 Need for Training on GAPs Uptake and Out-scaling to Other Communities

Under the GAPs overview (Fig. 2), the statement on the need for further support for farmers to adopt GAPs in dry lands through training and extension in the second and third rounds reached consensus. While in terms of the absolute ranking, in round 2, 10 people out of 11 scored 3 and over and in round 3, all 12 respondents scored 4 (100\%). Hence, a consensus was reached from the second round on the need for training to be carried out thereby informing the training and action planning in the two study communities. All participants in both rounds II and III agreed that farmers should be trained on GAPs and that the local knowledge and socio-economic conditions of the farmers should be considered in the generation, piloting and out scaling of GAPs. This is in line with increasing emphasis on the need for effective knowledge sharing methods for environmental sustainability and management as previously reported by Fazey et al. [24]. Interestingly, a participant in round $3(\mathrm{Ex} 4)$ asserted that dry lands

Table 5 Suggestions for improving the action plan from round 3.

\begin{tabular}{|c|c|c|}
\hline Practice & Expert (E) & -Suggestions \\
\hline \multirow[t]{4}{*}{$\begin{array}{l}\text { Practices under GAPs } \\
\text { overview }\end{array}$} & E11 & -Some extreme events or years require external support. \\
\hline & E4 & $\begin{array}{l}\text {-Dry lands deal with extremes that are beyond the capability of these farmers to tackle extreme } \\
\text { events. So the need for additional support. }\end{array}$ \\
\hline & E3 & $\begin{array}{l}\text {-Extension is needed for more enlightenment and pest and diseases' symptoms, management } \\
\text { and ecology. }\end{array}$ \\
\hline & E1 & -There is knowledge of GAPs but potentials exist for improved applications. \\
\hline \multirow[t]{3}{*}{$\begin{array}{l}\text { GAPs for soil fertility } \\
\text { management }\end{array}$} & E7 & -Leaving green manure on the surface is better than incorporation. \\
\hline & E7 & -Mixed cropping should be crop specific. \\
\hline & E4 & -Sustainable pastoralism should be defined. \\
\hline \multirow[t]{2}{*}{$\begin{array}{l}\text { GAPs for rainfall and } \\
\text { drought management }\end{array}$} & E12 & -With the availability of water. \\
\hline & E3 & -Agroforestry should be included. \\
\hline \multirow[t]{2}{*}{$\begin{array}{l}\text { GAPs for pests \& } \\
\text { diseases management }\end{array}$} & E4 & $\begin{array}{l}\text {-Use cover crops. } \\
\text {-Use natural enemies. }\end{array}$ \\
\hline & E3 & -Herbicides and pesticides should not be encouraged. \\
\hline $\begin{array}{l}\text { GAPs for degraded } \\
\text { land restoration }\end{array}$ & Ex4 & -If the production of mulch fits within the farming system. \\
\hline \multirow[t]{4}{*}{$\begin{array}{l}\text { GAPs potentials for } \\
\text { GHGs mitigation }\end{array}$} & E11 & -Earth bund and tied ridges may be in the long-term. \\
\hline & E3 & $\begin{array}{l}\text {-Re-vegetation should be specific either afforestation or any other practice. } \\
\text {-Zai is labour intensive as such its socio-economic benefits should be ascertained first. }\end{array}$ \\
\hline & E2 & -Some of the practices may not lead to GHGs mitigation. \\
\hline & E9 & $\begin{array}{l}\text {-Minimum tillage and intercrop should not be separate from conservation practices to avoid } \\
\text { duplication. }\end{array}$ \\
\hline \multirow[t]{2}{*}{$\begin{array}{l}\text { Additional practices } \\
\text { for resilience } \\
\text { enhancement }\end{array}$} & E6 & -Cropping systems are better than component technologies. \\
\hline & E5 & $\begin{array}{l}\text {-Community time-tested and tried indigenous practices and knowledge. } \\
\text {-Gender should be mainstreamed in the practices. }\end{array}$ \\
\hline
\end{tabular}

\footnotetext{
* Statement in bold affirmed the need for additional training on GAPs in the study areas.
} 
smallholders are faced with challenges beyond their capabilities, hence, the need for additional training for them to be adaptive, hence, providing a justification for the co-learning exercise.

Approaches to training (Fig. 3) suitable for GAPs uptake were also ranked in terms of the number of participants who scored 3 and over. Consensus was not reached in round 2 in terms of an absolute number of responses on all items but all items reached consensus in round 3 except for "training and visit" . Training and visit did not attain consensus at the round II with 5 out of 11 participants scoring 3 and over. However, it was retained at round III for the co-learning due to its importance though only $8(67 \%)$ out of 12 participants scored 3 and over in this item falling short of the $70 \%$ consensus mark selected for this study. Use of anchor farmers suggested in the round II for inclusion did not attain consensus at the round III so it was dropped and not included for co-learning. Some panel members suggested that these training options could better be utilised in an integrated fashion as opposed to using them in isolation. Hence, this suggestion was used in the co-learning activity.

3.4.2 GAPs on Soil Fertility Management in Tropical Dry lands

Practices for soil fertility management at round II all attained consensus apart from "Intensive control livestock (more animals)", which recorded no consensus. An expert argued that more livestock keeping was an old approach to dry land management that has proven to be a poor practice, hence it should be replaced by a more sustainable practice like "Sustainable pastoralism". As this practice was not applicable to the northern Nigerian dry land context, it was dropped. For both rounds in terms of an absolute number of panellists, all retained practices scored 3 and over $(\geq 82 \%)$ thereby forming a consensus (Fig. 1).

3.4.3 GAPs on Degraded Land Restoration in Tropical Dry Lands

All practices selected attained consensus based on absolute number count for rounds II and III. The attainment of consensus from the round 2 of revegetation (afforestation) justifies the merit of this practice for degraded land restoration as advocated in the agroforestry literature [25]. An expert in the round 2 (EX 9) argued that the GAPs were more centered on crop and neglecting livestock which is a key production form in the marginal areas. Despite the focus of the research been on crop production, some aspects of livestock were later incorporated to give a broader scope.

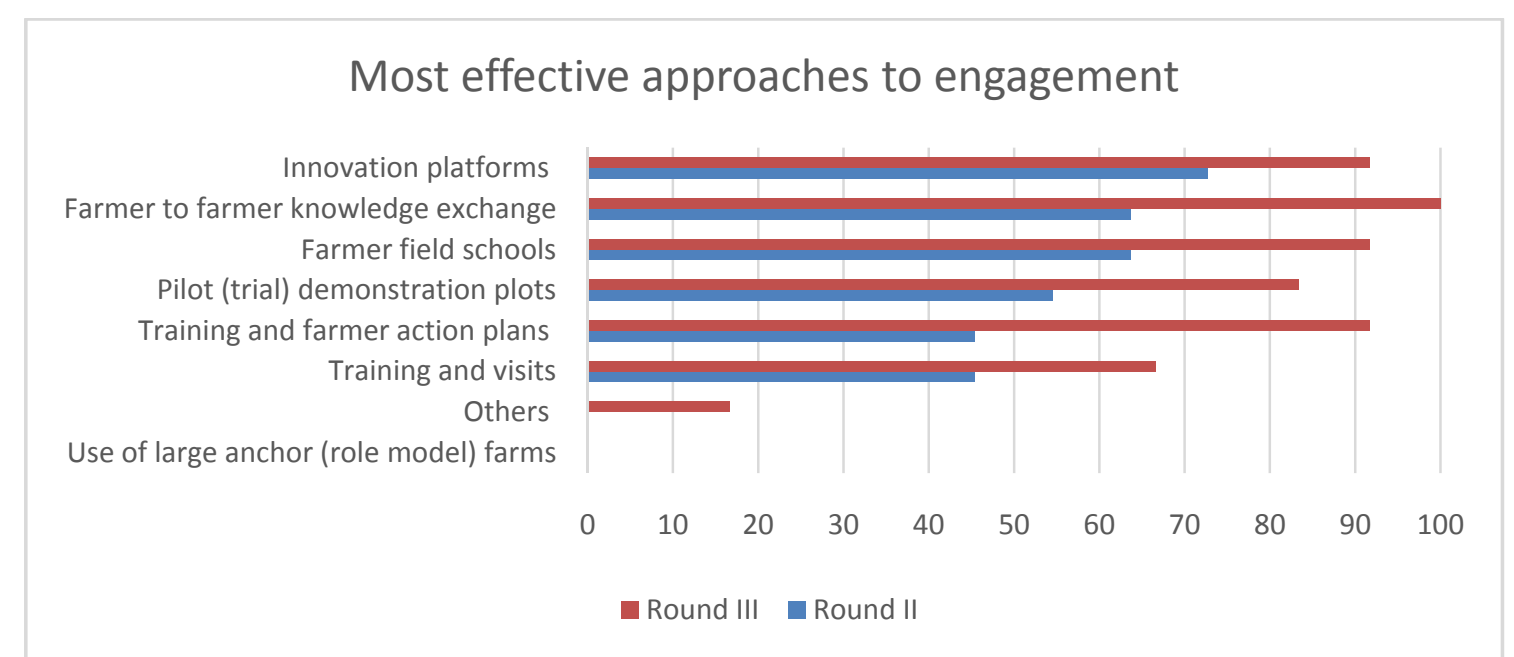

Fig. 3 Effective engagement of smallholders in up-taking GAP adaptation requires a combination of two or more of the following approach(es) in developing countries. 
3.4.4 GAPs on Rainfall and Drought Management in Tropical Dry Lands

The practices selected for low rainfall and drought management all attained consensus for the rounds II and III in terms of absolute numbers, they all recorded 3 and above in more than $70 \%$ responses on all items (Fig. 1). Hence, they were used for the training.

3.4.5 GAPs on Pest \& Diseases Management in Tropical Dry Lands

All practices for pest and diseases management apart from the destruction of crop residues attained consensus with absolute numbers high ( $73 \%$ and over) in both rounds II and III. However, a suggestion was made to modify "destruction of crop residue" to "destruction of diseased crop residue" which later attained consensus in the round III with $10(83 \%)$ out of 12 responses scoring 3 and above (Fig. 1).
3.4.6 Potentials of the GAPs in Mitigating Greenhouse Gas Emission in Tropical Dry Lands

In this section, all the practices highlighted above were assembled to understand their suitability for GHGs mitigation. "Roof top water harvesting" was suggested to be dropped after the round II for not being relevant for GHGs mitigation while two additional practices were suggested for inclusion for the round III; "Intercropping legumes with other crops", and "Use of cover crops" with "sustainable pastoralism" also replacing "intensive control livestock grazing". Being a binary (Yes and No) question, descriptive statistics (bar chart) was employed since the level of measurement determines the type of statistical test to be employed [18]. Hence, "yes" responses were used to decipher expert opinion on the suitability of the practices for GHGs mitigation.

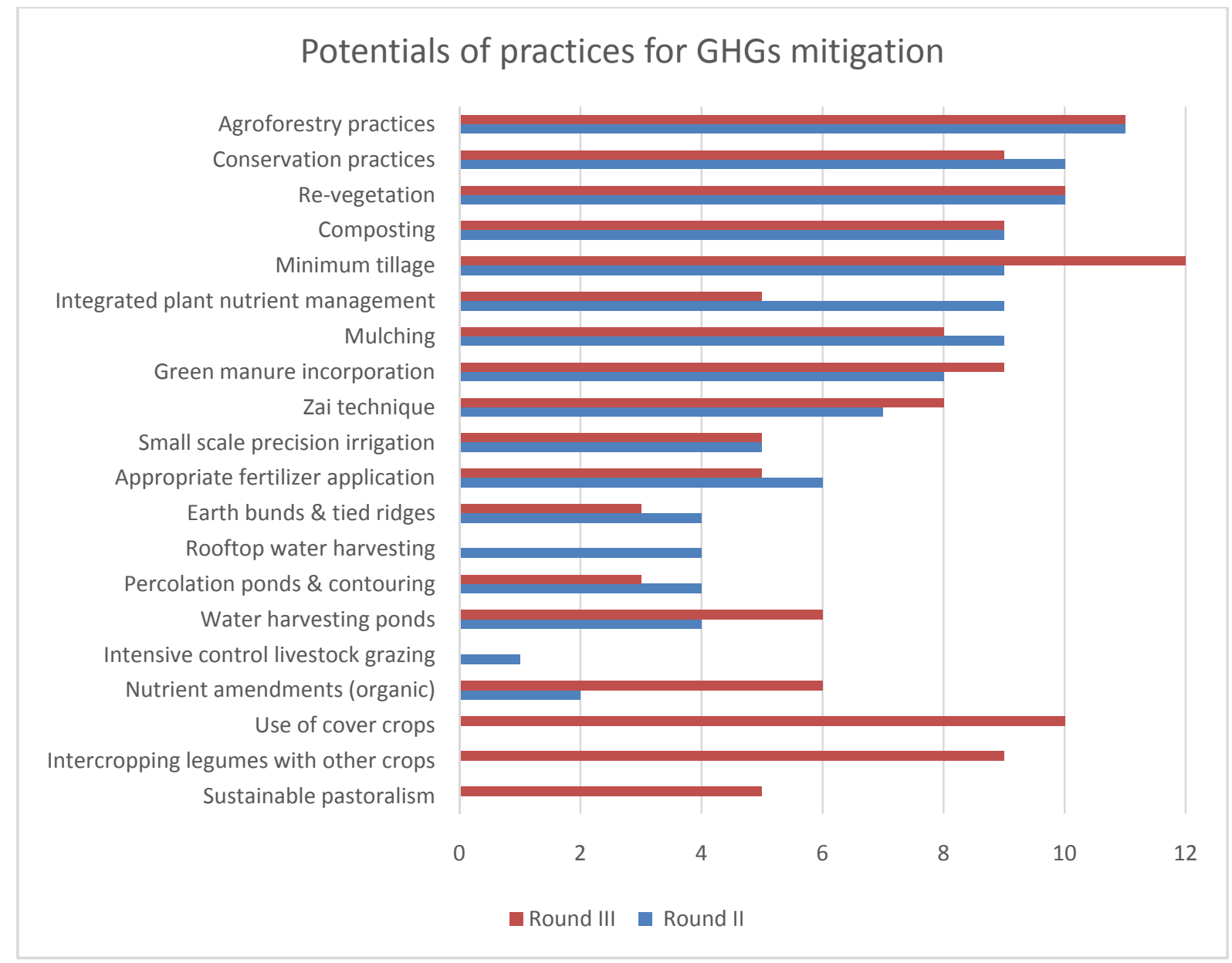

Fig. 4 GAPs in dry lands with potential for GHGs mitigation rounds II \& III. 
The results show that agroforestry, conservation agricultural practices and "re-vegetation" had the highest positive values for the two rounds implying higher consensus as the most important practices in terms of GHGs mitigation in tropical dry lands (Fig. 4). This agrees with the findings of the FAO [25] that agroforestry is a very important climate smart practice. This was further emphasized by Ref. [26], arguing that it is increasingly important to pursue environmental conservation techniques in growing the local economy to be sustainable as incremental benefits of additional input has declined over the years.

Some of the responses recorded negative values as some panel members argued that the practices are context specific and dependent on land use. Hence, it may be difficult to generalize their applicability for greenhouse gas mitigation.

\section{Conclusions}

This paper has elicited experts' opinion of GAPs and their suitability for soil fertility improvement, rainfall and drought management, degraded land restoration, with preferred methods of training and the potentials for GHGs mitigation of those practices. The results from the two rounds were analyzed and adapted into farmer action plans. Although most participants' responses are biased towards their own area of specialty, the wide range of expertise was useful in gathering varied perspectives on dry land management. Delphi technique may not be a definitive method, however, if appropriately utilized, it offers opinions from an array of experts on a specific topic [18]. In this study, the Delphi technique validated the use of GAPs appropriate for ensuring agriculture is practiced in the era of climate change to enhance food security of households while ensuring environmental sustainability and resilience of food system components in dry lands of north-western Nigeria. More so, that the subsequent co-learning interventions were more evidence based and further underpinned the use of the Delphi technique as a decision-support tool [7]. This study is important because increased crop output in most developing countries will be expected from agricultural intensification on existing land rather than land expansion as arable land has been exhausted [26]. Although this study has succeeded in capturing the views of experts from broad disciplinary areas related to the subject of study, it will be interesting for further studies to consider participants with different characteristics from these ones to compare variation in responses. The findings from this paper informed training and co-learning of farmers in the study communities on soil fertility, drought, and degraded land management and the results reported in a later paper.

\section{Acknowledgements}

Special thanks go to the National Biotechnology Development Agency, Abuja-Nigeria for granting study leave to the corresponding author.

We thank the reviewers for their comments and suggestions. We are solely responsible for all errors and misrepresentations.

\section{Funding}

This research did not receive any specific grant from funding agencies in the public, commercial, or not-for-profit sectors.

\section{References}

[1] Kuhnert, P. M., Martin, T. G., and Griffiths, S. P. 2010. "A Guide to Eliciting and Using Expert Knowledge in Bayesian Ecological Models." Ecology Letters 13: 900-14.

[2] Martin, T. G., Burgman, M. A., Fidler, F., Kuhnert, P. M., Low-Choy, S., McBride, M., and Mengersen, K. 2012. "Eliciting Expert Knowledge in Conservation Science." Obtención de Conocimiento de Expertos en Ciencia de la Conservación 26 (1): 29-38.

[3] Hsu, C. C., and Sandford, B. A. 2007. "The Delphi Technique: Making Sense of Consensus." Practical Assessment, Research \& amp; Evaluation 12 (10): 1-8.

[4] Yousuf, M. I. 2007. "Using Experts' Opinions through Delphi Technique." Practical Assessment, Research \& 


\section{A Delphi Approach to the Selection of Good Agricultural Practices (GAPs) for Resilience Enhancement for Dry Land Farmers in North-Western Nigeria}

Evaluation 12 (4): 1-8

[5] Robson, C. 2011. Real World Research: A Resource for Users of Social Research Methods in Applied Settings. 3rd ed. Wiley \& Sons.

[6] RAND CORPORATION. 2017. Delphi Method | RAND. [online] Available from: https://www.rand.org/topics/delphi-method.html [Date accessed: 15/05/2017].

[7] Landeta, J. 2006. "Current Validity of the Delphi Method in Social Sciences." Technological Forecasting and Social Change 73 (5): 467-82.

[8] Linstone, H. A., and Turoff, M. 2002. "Introduction." The Delphi Method: Techniques and Applications. Edited by Linstone, H. A., and Turoff, M. Newark: New Jersey Institute of Technology, 3-12.

[9] Okoli, C., and Pawlowski, S. D. 2004. "The Delphi Method as a Research Tool: An Example, Design Considerations and Applications." Information \& Management 42 (1): 15-29.

[10] Fisher, C. 2010. Researching and Writing a Dissertation: An Essential Guide for Business Student's. Third ed. Pearson Education Limited.

[11] Gordon, T. J. 1994. "The Delphi Method. Futures Research Methodology." Available from: http://fpf.ueh.edu.vn/imgnews/04-Delphi.pdf.

[12] Chu, H. C., and Hwang, G. J. 2008. "A Delphi-based Approach to Developing Expert Systems with the Cooperation of Multiple Experts." Expert Systems with Applications 34 (4): 2826-40.

[13] Grundy, M., and Ghazi, F. 2009. "Research Priorities in Haemato-Oncology Nursing: Results of a Literature Review and a Delphi Study." European Journal of Oncology Nursing 13: 235-49.

[14] Vidal, L. A., Marle, F., and Bocquet, J. C. 2011. "Using a Delphi Process and the Analytic Hierarchy Process (AHP) to Evaluate the Complexity of Projects." Expert Systems with Applications 38 (5): 5388-405.

[15] Wentholt, M. T. A., Fischer, A. R. H., Rowe, G., Marvin, H. J. P., and Frewer, L. J. 2010. "Effective Identification and Management of Emerging Food Risks: Results of an International Delphi Survey." Food Control 21 (12, Supplement): 1731-8.

[16] Lozano, L. M., García-Cueto, E., and Muñiz, J. 2008. "Effect of the Number of Response Categories on the Reliability and Validity of Rating Scales." Methodology 4 (2): 73-9.
[17] Soon, J. M., Davies, W. P., Chadd, S. A., and Baines, R. N. 2012. "A Delphi-based Approach to Developing and Validating a Farm Food Safety Risk Assessment Tool by Experts." Expert Systems with Applications 39 (9): 8325-36.

[18] Hasson, F., Keeney, S., and McKenna, H. 2000. "Research Guidelines for the Delphi Survey Technique." Journal of Advanced Nursing 32 (4): 1008-15.

[19] Powell, C. 2003. "The Delphi Technique: Myths and Realities." Journal of Advanced Nursing 41 (4): 376-82.

[20] Scapolo, F., and Miles, I. 2006. "Eliciting Experts' Knowledge: A Comparison of Two Methods. Technological." Forecasting and Social Change 73 (6): 679-704.

[21] Keeney, S., Hasson, F., and McKenna, H. P. 2001. "A Critical Review of the Delphi Technique as a Research Methodology for Nursing." International Journal of Nursing Studies 38 (2): 195-200.

[22] Scheibe M., Skutsch, M., and J. Schofer, J. 2002. "Experiments in Delphi Methodology." The Delphi Method: Techniques and Applications. Edited by Linstone, H. A., and Turoff, M. Newark: New Jersey Institute of Technology, 257-81.

[23] Steinert, M. 2009. "A Dissensus Based Online Delphi Approach: An Explorative Research Tool." Technological Forecasting and Social Change 76 (3): 291-300.

[24] Fazey, I., Evely, A. C., Reed, M. S., Stringer, L. C., Kruijsen, J., White, P. C. L., Newsham, A., Jin, L., Cortazzi, M., Phillipson, J., Blackstock, K., Entwistle, N., Sheate, W., Armstrong, F., Blackmore, C., Fazey, J., Ingram, J., Gregson, J. O. N., Lowe, P., Morton, S., and Trevitt, C. 2013. "Knowledge Exchange: A Review and Research Agenda for Environmental Management." Environmental Conservation 40 (1): 19-36.

[25] FAO. 2009. "Food Security and Agricultural Mitigation in Developing Countries: Options for Capturing Synergies." [online] FAO. Available from: http://www.fao.org/docrep/012/i1318e/i1318e00.pdf [Date accessed: 14/10/2016]

[26] Vosti, S. A., and Reardon, T. 1997. "Introduction: The Critical Triangle of Links among Sustainability, Growth, and Poverty Alleviation." Sustainability, Growth, and Poverty Alleviation: A Policy and Agroecological Perspective. Edited by Vosti, S. A., and Thomas, R. Baltimore: The Johns Hopkins University Press, 1-15. 